\title{
HORMÔNIOS NA PRODUÇÃO DE MODOS DE SUBJETIVAÇÃO: ATUANDO CONTROVÉRSIAS
}

\author{
LAS HORMONAS EN LA PRODUCCIÓN DE MODOS DE \\ SUBJETIVACIÓN: ACTUANDO CONTROVERSIAS \\ HORMONES IN THE PRODUCTION OF FORMS \\ OF SUBJECTIVATION: ACTING CONTROVERSIES
}

\author{
Juliana Sampaio e Benedito Medrado² \\ ${ }^{1}$ Universidade Federal do Ceará, Fortaleza/CE, Brasil \\ ${ }^{2}$ Universidade Federal de Pernambuco, Recife/PE, Brasil
}

RESUMO: Este artigo visa analisar agenciamentos produzidos pelos hormônios na conformação de modos de subjetivação contemporâneos. A abordagem teórico-metodológica adotada se alinha aos estudos de Michel Foucault, especialmente em seus escritos sobre modos de subjetivação, e se aproxima de alguns conceitos postulados por pesquisadores alinhados à Teoria Ator-Rede (TAR), que nos ajudam a compreender aspectos relativos aos hormônios como atuantes na conformação dos modos de subjetivação. O corpus de análise foi constituído a partir de vídeos disponibilizados publicamente pela indústria farmacêutica Bayer, totalizando 34 vídeos. Concluímos que os hormônios têm produzidos efeitos diversos, entre eles a atualização do modelo binário de sexo, que, entre outras coisas, associa a mulher à função reprodutiva e os homens ao exercício da sexualidade. Tais premissas normatizadoras instituem determinados modos de subjetivação e constrangem a diversidade e a plasticidade.

PALAVRAS-CHAVE: Hormônios; Modos de Subjetivação; Dispositivo; Ator-rede.

RESUMEN: Este artículo tiene como objetivo analizar los conjuntos producidos por las hormonas en la configuración de los modos de subjetivación contemporánea. El enfoque teórico y metodológico adoptado está en consonancia con los estudios de Michel Foucault, especialmente en sus escritos sobre los modos de subjetivación, y se acerca de algunos conceptos postulados por los investigadores alineados a la Teoría Actor-Red (ART), que nos ayudan a entender los aspectos relacionados con las hormonas como actuantes en la conformación de los modos de subjetividad. El corpus de análisis se hizo a partir de 34 vídeos puestos a la disposición del público por parte de la industria farmacéutica Bayer. Concluimos que las hormonas han producido varios efectos, entre ellos la actualización del modelo binario de sexo, que, entre otras cosas, asocia la mujer a la función reproductiva y los hombres al ejercicio de la sexualidad. Tales suposiciones reguladoras establecen determinados modos de subjetivación y limitan la diversidad y la plasticidad.

PALABRAS CLAVE: Hormonas; Modos de Subjetivación; Dispositivo; Actor-red.

ABSTRACT: This publication aims to analyze hormone-produced actions in the conformation of contemporary forms of subjectivation. The theoretical-methodological approach adopted is aligned with the studies of Michel Foucault, especially in his studies on forms of subjectivation and approaches some concepts postulated by researchers aligned with the Actor-Network Theory (ANT) that help us to understand aspects related to hormones as actors in the conformation of forms of subjectivation. The corpus of analysis consisted of videos made publicly available by the pharmaceutical industry Bayer, totaling 34 videos. We conclude that hormones have produced diverse effects, among them the updating of the binary sex model, which, among other things, associates women with the reproductive function and men with the exercise of sexuality. Such normative premises institute certain forms of subjectivation and constrain diversity and plasticity.

KEYWORDS: Hormones; Forms of subjectivation; Device; Actor-network. 


\section{Introdução}

Este artigo busca dar visibilidade a formas diversas a partir das quais os hormônios contribuem na produção de modos de subjetivação contemporâneos. Assim, os hormônios são o objeto central desta pesquisa, a partir da qual buscaremos analisar os agenciamentos produzidos por essas substâncias, especialmente, na conformação e deslocamentos de modos de subjetivação. Nesse sentido, os modos de subjetivação são definidos pelas maneiras como nos relacionarmos com as regras estabelecidas em cada período histórico, eles dizem respeito à forma predominante desta relação (Nardi, 2006).

Para essa análise, focalizaremos material disponibilizado na plataforma online do Youtube, por uma das principais indústrias farmacêuticas multinacionais, responsável não apenas por produção de hormônios em larga escala, como também pela popularização desses fármacos: a Bayer.

Os hormônios integram uma rede complexa que subverte as normas e regras que determinados saberes, como o biomédico, tentam impor. Integram também essa rede os sujeitos que administram essas substâncias, pois as utilizam de diferentes modos, resistindo às prescrições instituídas, a despeito de uma possível intencionalidade subversiva. Nesse sentido, os hormônios se configuram como elementos importantes na rede de produção de modos de subjetivação na nossa sociedade, provocando efeitos diversos.

Os hormônios configuram-se, assim, como "atuantes" ou, nas palavras de Bruno Latour, como "mediadores que transformam, traduzem, distorcem e modificam o significado dos elementos que se supõe que devem carregar, ou seja, não se posicionam de maneira estanque como meros intermediadores" (Latour, 2012, p. 65). E, como atuantes, os hormônios têm assumido importância nas formas de "relação consigo", produzindo novas conformações de "eus".

Assim, essas substâncias podem se configurar também como uma estratégia contínua de poder, na medida em que o corpo se constitui em ferramenta de governo que se exacerba com a administração de hormônios, ao mesmo tempo em que essas estratégias de controle pelo/sobre o corpo (compreendido aqui como superfície de inscrição da verdade e foco de intervenção política) se confundem e se misturam (Hüning, 2008; Preciado, 2008; Souza, Galindo, \& Bertoline, 2012).

Nesta leitura, fazemos um paralelo com os hormônios e a discussão de Simone Hüning (2008) a respeito das biotecnologias, pois podemos considerar os hormônios como biotecnologia, já que esses produzem:

Um paradoxo de simultânea "incorporação" da "subjetividade" e "desmantelamento" do corpo, que já não se define em termos de órgãos e funções, mas de suas mínimas unidades de informação genética, molecular. Concomitantemente, o próprio indivíduo torna-se um mero conglomerado de informações que já não provêm de corpos individuais, mas ... que já não distingue o humano e o não-humano, mas que ao contrário, o recombina incessantemente. Em meio a esta complexa rede (científica, tecnológica, comercial, econômica, legal, moral...) o biológico que se produz com os recursos biotecnológicos se torna uma referência, e até mesmo uma condição, para a constituição da experiência do sujeito contemporâneo. (Hüning, 2008, p. 98) 
Nesse sentido, os hormônios não estão envolvidos apenas na trama relativa aos processos de saúde e adoecimento, mas no imperativo de felicidade e realização pessoal, que articula padrões de aparência, de afetos, de feminilidade e masculinidade. Os hormônios atuam como dispositivo de governo de si, atrelado às mudanças que são imprevisíveis, tendo efeitos variados de acordo com a rede em que se estabelece (Galindo, Vilela, \& Moura, 2012).

Dessa forma, um estudo sobre hormônios no campo da Psicologia se justifica especialmente por suas possíveis aberturas para leituras sobre produção de modos de subjetivação contemporâneos, atravessados pelo poder biomédico e pela tecnologia farmacológica. Os hormônios não possuem, assim, propriedades inerentes, mas múltiplos efeitos possíveis que se produzem a partir de diferentes práticas. Compreendemos, então, que essas substâncias atuam e são atuadas (Latour, 2012).

Nessa perspectiva, buscamos discutir a importância de agregar elementos não humanos às pesquisas da Psicologia, pois esses possuem agência e participam das ações. Com isso, definimos como objetivo desta pesquisa analisar agenciamentos produzidos pelos hormônios na conformação/deslocamentos de modos de subjetivação contemporâneos. Para tal empreendimento, foram analisados vídeos disponibilizados no Toutube pela Bayer, como descreveremos com mais detalhes no próximo tópico.

\section{Método}

Neste trabalho, não partimos de um campo teórico circunscrito, com conceitos ou métodos delimitados. Ao contrário, tomamos por base uma abordagem teórico-metodológica construída, por um lado, a partir de uma perspectiva crítica ao modo de produção científica e sua leitura especular instituída na Modernidade e, por outro, a partir da bricolagem de conceitos e estratégias analíticas, num esforço inspirado em Marcos Neira e Bruno Lippi (2012), segundo os quais:

na bricolagem não se busca descobrir verdades, como se elas estivessem escondidas à espera de um investigador, o que se pretende é entender a sua construção e questionar como os diversos agentes sociais produzem e reproduzem o que é imposto pelos discursos hegemônicos. Ora, teorias e conhecimentos nada mais são do que artefatos culturais e linguísticos. Uma vez que a interpretação está imbricada na dinâmica social e histórica que moldou o artefato cultural sob análise, a bricolagem reconhece a inseparabilidade entre objeto de pesquisa e contexto. Consequentemente, a linguagem e as relações de poder assumem a posição central nas interpretações da realidade, pois se constituem como mediadores fundamentais na contemporaneidade. (p. 610)

Em nossa bricolagem, alinhamo-nos aos estudos de Michel Foucault (2009, 2010), especialmente em sua definição sobre modos de subjetivação, e nos aproximamos de alguns conceitos postulados por pesquisadores/as alinhados/as à Teoria Ator-Rede (TAR), que nos ajudam a compreender alguns aspectos relativos aos hormônios como agenciadores de práticas e de modos de subjetivação.

Nesta pesquisa, optamos por desenvolver um estudo particular tendo como artefato analítico o material produzido e veiculado por uma empresa multinacional responsável por fabricação e comercialização de hormônios. 
A escolha deste material teve como parâmetros a diversidade de práticas discursivas e não discursivas que tais documentos fazem circular (Spink, Brigagão, Nascimento, \& Cordeiro, 2014). Além disso, a opção por analisar vídeos veiculados na Internet possibilitou a aproximação com os saberes que o público leigo, em relação aos estudos sobre hormônios, podem, também, facilmente acessar. Com isso, entendemos que tais materiais, quando articulados em rede, possibilitam a produção de diferentes modos de subjetivação.

Estes materiais são aqui concebidos como “documentos de domínio público”, expressão cunhada por Peter Spink (2004), para referir-se, em linhas gerais, àquilo que definiríamos como práticas discursivas que promovem circulação de saberes e, portanto, podem nos auxiliar tanto em análises sobre efeitos de verdade como também na explicitação de controvérsias, agências e resistências.

Consideramos que esses embates entre práticas cristalizadas e resistências são constituintes dos processos de negociação de informações e fundamentais para entendermos os diferentes modos de viver em nossa sociedade. Nesse sentido, concordamos com Méllo quando enfatiza o público como espaço de veiculação e atualização de universais.

As fontes documentais foram incorporadas ao próprio cotidiano da cultura letrada e são instrumentos que divulgam e debatem esse cotidiano e até buscam a sua normalização. Assim, a pesquisa que toma como base de análise fontes documentais faz com que saiam da sombra, deixem de ocupar o lugar de "fontes secundárias". Os documentos fazem parte da política, entendida, sob inspiração de Foucault, como "estética da existência": a busca de dar um sentido às existências individuais, rechaçando uma política instrumental, que pretenda fazer vigorar o espaço público como veiculador e atualizador de ideias universais. (Méllo, 2006, p. 60)

Dessa forma, os documentos são ao mesmo tempo produtos e produtores de práticas sociais. E tal característica faz com que eles sejam importantes instrumentos de governo, atuem no gerenciamento dos corpos. Essa particularidade dos documentos permite que sejam analisados não só os saberes e as relações de poder como também a produção de modos de subjetivação.

Compreendemos que os documentos não são simplesmente meros mediadores (entre verdade e produção discursiva sobre ela), mas que possuem agência, isto é, produzem efeitos a partir das relações que estabelecem em rede (Latour, 2001, 2009). Desse modo, os vídeos que foram analisados nesta pesquisa são compreendidos como atuantes, pois ele agenciam diferentes práticas.

A indústria farmacêutica Bayer foi escolhida dentre uma diversidade de companhias desse seguimento, pois além de ter 26 (vinte e seis) medicamentos voltados para os "hormônios sexuais", sendo 2 (dois) desses específicos para a regulação da testosterona, essa empresa também possui uma ampla rede de informações on-line. Dessa forma, buscamos mapear por quais meios as indústrias farmacêuticas atingiam o seu público consumidor.

O grupo Bayer se mostrou bastante produtivo, logo no início do nosso mapeamento, pois já no seu site principal, voltado para o público brasileiro, www.bayer.com.br, aparece no cabeçalho superior o ícone mídia que apresenta os seguintes subitens: notícias, comunicados, sala de imprensa, websites Bayer, Apps Bayer, contatos para imprensa e publicações.

Dentre a variedade de plataformas na qual a Bayer está inserida, nos chamaram a atenção, particularmente, os vídeos divulgados no Toutube, pois apresentavam de modo 
dinâmico uma série de informações relacionadas à saúde e muitas vezes de forma mais intimista, como uma conversa. No Toutube a Bayer possui 6 (seis) canais oficiais: (a) Bayer Brasil; (b) Expressão Feminina; (c) Bayer Group; (d) Bayer Saúde animal; (e) CropScience; (f) Bayer TV internacional, sendo este último em língua inglesa.

Após assistir todos os vídeos de todos os canais, selecionamos os conteúdos que seriam mais interessantes para esta pesquisa. Construímos, então, um quadro organizando os vídeos em relação ao seu conteúdo e público, com todos os vídeos dos canais Expressão Feminina e Bayer Brasil, pois estes apresentavam, além de informações sobre doenças, propagandas veiculadas na televisão, os vídeos sobre hormônios, foco do nosso estudo. $\mathrm{O}$ quadro apresenta o nome dos vídeos, links, descrição dos vídeos, número de visualizações e tempo de duração desses.

Estão disponibilizados no canal Expressão Feminina o total de 56 vídeos, que tratam de temas diversos desde endometriose a tratamento para estria, sendo que 31 desses vídeos discutem temas que perpassam os hormônios. No canal Bayer Brasil estão disponíveis 31 vídeos com conteúdo bastante variado que trata desde propagandas de remédios analgésicos até uma reportagem sobre uma campanha da Bayer no dia do homem; dentre esses vídeos, apenas 3 abordam a temática hormônios, especificamente os "masculinos".

Todos os 34 vídeos que falam sobre os hormônios, mesmo que transversalmente, foram transcritos e organizados da última publicação à primeira, de acordo com a ordem em que aparecem no routube.

Os 34 vídeos selecionados foram assistidos novamente, agora com a leitura paralela das transcrições para verificar possíveis erros no material transcrito. Em sequência, após uma nova leitura das transcrições, foram selecionados os conteúdos que seriam de maior importância para este estudo, pois discutem os hormônios especificamente e seus efeitos. Os trechos selecionados foram separados em um arquivo específico e depois organizados em função do foco das análises.

Para o desenvolvimento de nossas análises, realizamos um exercício inspirado na cartografia de controvérsias, proposto por Bruno Latour (2007) e aplicado por Mariana Moreira (2014) em sua tese de doutorado.

Como bem destaca Moreira (2014), este exercício compreende as estratégias metodológicas que, propositalmente, afastam-se do "apaziguamento e do silenciamento dos ruídos, embates e dissonâncias em busca de ferramentas que façam reverberar sons, multiplicar vozes" (p. 36).

Assim, segundo a autora, ao propormos traçar uma cartografia de controvérsias, reconhecemos a produção de conhecimento como um processo-intervenção que reconhece seu caráter processual, situando sua parcialidade, incompletude e provisoriedade.

O resultado esperado não aponta sínteses ou generalizações, mas a configuração de um mosaico composto por múltiplas vozes e experiências diversas que permitam recriar utopias, sentidos e possibilidades de reinvenção de modos de ser, conhecer e viver juntos. (Moreira, 2014, p. 37)

Para a produção dessas controvérsias, o material selecionado foi organizado em duas grandes curvas de análise, em consonância com os objetivos da pesquisa: (a) estabelecer relações entre os saberes sobre os hormônios e a produção de efeitos de verdade; e (b) analisar os hormônios na produção/regulação de feminilidades e masculinidades. 
A escolha por tais curvas de análise não foi realizada a priori, mas a partir do campo-tema, com diversas leituras das transcrições e assistindo várias vezes os vídeos selecionados. Salientamos que outras curvas de análise poderiam ter sido produzidas, pois o material é extenso e complexo, mas essas foram as selecionadas para a presente pesquisa, levando em conta os objetivos deste estudo para a organização do material.

Vale salientar que as curvas de análise se articulam em torno do eixo central desta pesquisa que, como dito anteriormente, visa a analisar agenciamentos produzidos pelos hormônios na conformação/deslocamentos de modos de subjetivação contemporâneos.

Além dos conteúdos, analisamos também os cenários dos vídeos, quem eram os convidados (sexo, cor, idade, profissão), quem falava e como falava. Como os diálogos eram encadeados, a mudança de cenário e a forma de abordar os conteúdos, se o público-alvo era mulheres ou homens.

Os sujeitos que falam nos vídeos associados à Bayer incitam reflexões, prescrevem condutas, recomendam produtos, isto é, produzem modos de viver, ajudando o público a conduzir a si mesmo. No próximo tópico, analisaremos com mais detalhes os agenciamentos produzidos pelos hormônios na conformação de modos de subjetivação contemporâneos.

\section{Resultados e discussão}

Tendo como referência as curvas de análise citadas anteriormente, organizamos os nossos resultados em três grandes campos temáticos que se dividem em subtópicos:

1. Saber biomédico e produção de efeitos de verdade: medicalização da vida, sexualidade como objeto de medicalização, direitos sexuais e reprodutivos, gestão do risco, prevenção como instrumento de regulação.

2. Hormônios na produção/regulação de feminilidades: naturalização da reprodução e maternidade, reposição hormonal e normatização do envelhecimento, oscilação hormonal e instabilidade da mulher.

3. Hormônios na produção/regulação de masculinidades: saúde do homem, saúde sexual, envelhecimento e ereção, masculinidades e reprodução.

Discutiremos, então, as controvérsias atuadas pelos hormônios a partir dos pontos elencados acima. Tal organização em tópicos nos ajuda a explicitar alguns dos possíveis arranjos temáticos dentro da diversidade dos conteúdos apresentados no material analisado.

\section{Saber biomédico e produção de efeitos de verdade}

Tendo como referência os vídeos da Bayer, analisamos que os hormônios se articulam com saber biomédico na produção de efeitos de verdade a partir da medicalização da vida e da sexualidade, da gestão do risco e das práticas de prevenção na saúde. Percebemos em todos os vídeos a presença de profissionais da saúde, sendo esta uma das estratégias utilizadas pela Bayer para maior aproximação com o público consumidor, a partir do encontro entre o discurso científico e o discurso midiático.

Por meio das plataformas online, a Bayer faz circular os saberes científicos por meio da publicação de pareceres médicos, resultados de pesquisas, dicas de saúde e, com isto, promove também, direta ou indiretamente, a divulgação dos seus produtos farmacêuticos. 
Podemos perceber que os hormônios têm se articulado com uma série de elementos, produzindo determinados modos de subjetivação na nossa sociedade. Porém, além de se associar com o discurso biomédico e estratégias de medicalização da sexualidade, os hormônios também estão envolvidos na luta pelos direitos sexuais e reprodutivos.

Regina Bittar: Quais são os principais avanços na medicina que contribuíram para a melhoria da qualidade de vida da mulher?

Dr. Rogério: Olha, nós não poderíamos deixar de falar da pílula anticoncepcional como um dos pontos altos dessa.

Regina Bittar: É verdade, 50 anos, né?

Dr. Rogério: Fazendo 50 anos agora. A história da pílula levou consigo todas essas expectativas da mulher, a mulher consegue planejar sua família, consegue fazer mais coisas do que ela fazia antigamente. E outra, ela consegue algumas melhoras que são tão sensiveis que nós não conseguimos detectar. Por exemplo, hoje, quando se usa um anticoncepcional, a mulher está pouco preocupada com a eficácia porque ela sabe que todas as pílulas são eficazes, mas ela quer mais do que um anticoncepcional, ela quer beleza, ela quer pele melhor, ela quer melhoras dos sintomas. (Bayer, $2011 \mathrm{a}$ )

A primeira controvérsia que buscamos visibilizar em relação aos hormônios é: essas substâncias atuam de forma ambígua no campo de disputa entre o saber biomédico e os direitos sexuais e reprodutivos, na medida em que têm sido utilizadas tanto para garantir tais direitos como também para se contrapor a essas demandas, medicalizando a sexualidade (Rohden \& Russo, 2011).

Os hormônios agenciam possibilidades para as mulheres lutarem pelo direito ao seu próprio corpo, tendo a possibilidade de escolha sobre querer engravidar ou não, porém, há, também, uma propagação simultânea dos discursos que enfatizam a importância da ampla distribuição e acesso aos métodos contraceptivos, entre eles os anticoncepcionais (Rohden, Russo, \& Giami, 2014). Destacamos que este último discurso de ampla distribuição de métodos contraceptivos de base hormonal se associa ao processo de medicalização da sexualidade, que se organiza a partir de uma perspectiva biologizante do ser humano e que também torna todas as práticas de saúde uma questão a ser gerida pelo saber biomédico.

Tal gestão da saúde reprodutiva e sexual também se alinha à gestão do risco na nossa sociedade, na qual os hormônios têm agenciado inúmeras práticas. Essas substâncias aparecem no discurso médico tanto como produtoras de risco como também protetoras de risco, sendo a segunda controvérsia a ser destacada no presente estudo (Rose, 2013). Tais práticas têm produzido, potencializado ou deslocado modos de subjetivação em nossa sociedade.

O saber biomédico busca gerir os riscos associados aos hormônios, afirmando que tais substâncias podem prevenir riscos futuros. Os hormônios se situam de modo ambíguo nesse campo de disputa, pois seriam ao mesmo tempo produtores e protetores de risco. Dessa forma, buscamos tencionar a noção de risco associado aos hormônios considerando, por um lado, que os hormônios se configuram como tentativa de controle do futuro, mas também como tecnologia de controle e gestão dos corpos, principalmente os femininos, engendrando uma série de práticas que institucionalizam determinados modos de ser mulher, como discutiremos no próximo tópico. 


\section{Hormônios na produção/regulação de feminilidades}

Dentre os agenciamentos produzidos pelos hormônios, interessa-nos particularmente os que estão associados ao sexo e sexualidade, particularmente na naturalização do dimorfismo sexual. Dessa forma, destacamos para discussão as questões relacionadas aos hormônios na conformação de práticas de feminilização. Os principais subtemas articulados às práticas de feminilização são: a naturalização da reprodução e maternidade, a reposição hormonal e normatização do envelhecimento, a oscilação hormonal e instabilidade atribuída às mulheres.

A função reprodutiva da mulher continua como sua atividade primordial e natural, mesmo ou principalmente com a construção de novos aparatos tecnológicos pela medicina (Rohden, 2000). Os hormônios, os óvulos congelados, a fertilização in vitro são atuantes importantes na rede que consagra a mulher como a principal responsável pela reprodução e consequentemente pelo exercício de cuidado com os filhos.

Os hormônios não agenciam sozinhos o lugar central da mulher na reprodução, mas se associam, por exemplo, com elementos históricos, como o domínio da medicina sobre o corpo da mulher e o controle do crescimento populacional. No Brasil, configurado como país emergente, essas substâncias influenciam o intenso controle dos corpos das mulheres de baixa renda, principalmente, e sua capacidade reprodutiva a partir da distribuição e consumo massivo de contraceptivos hormonais (Matos, 2003; Pedro, 2003).

Regina: Não, nenhuma das minhas gestações foram planejadas.

Regina Bittar: Nenhuma delas? Mas você usava algum método contraceptivo?

Regina: Olha, a princípio eu fazia tabelinha. Ai eu passei a usar anticoncepcional.

Regina Bittar: A tabelinha é um perigo.

Doutora: A tabelinha é um método que tem uma taxa de falha alta e na presença hoje de tantos métodos eficazes ela acabou hoje sendo abandonada, mas enfim, cada caso é um caso e tem mulheres que realmente só sobra esse método comportamental, mas é muito pouco usado.

Regina: Então, e depois com o tempo o meu marido resolveu usar camisinha.

Regina Bittar: Porque ele tinha medo?

Regina: Também, no terceiro filho ele quase teve um...

Doutora: Para mim chega de tabelinha.

Regina: É, não quis mais tabelinha.

Regina Bittar: Você acha que isso faz diferença você planejar sua vida, vocêfala com as suas filhas sobre isso? 
Regina: Eu vou falar uma coisa, a minha filha mais velha é completamente planejada na vida dela, então hoje ele tem 26 anos e ela tem a casa dela, ela tem o emprego dela, ela tem a vida dela muito bem planejada, tanto que ela só quer ter filhos após os 30 anos, ela quer se manter, se formar em tudo, ter uma base mais sólida para ela poder depois pensar em ter um filho. Porque realmente, né, filho é uma coisa séria, então eu acredito que a gente tenha que ter uma estrutura lá atrás para poder assumir um filho lá na frente. (Bayer, $2011 \mathrm{~b}$ )

Destacamos, então, a terceira controvérsia que envolve o uso de hormônios, pois o seu uso como contraceptivo possibilita tanto o controle da mulher sobre sua vida reprodutiva como também a coloca como a única responsável pela gravidez. A pílula anticoncepcional agenciou uma série de mudanças na vida das mulheres, ela pôde ser tanto fonte de liberdade sexual, aspecto importante para a luta feminista, como pôde ser usada para controlar moralmente o processo reprodutivo.

Os hormônios têm agenciado não só a renaturalização da essência materna da mulher, mas também sua natureza instável devido à oscilação hormonal que a afetaria ao longo de cada mês, bem como de toda a vida. O saber biomédico tem sido historicamente utilizado para justificar não só a gravidez ou a amamentação, mas também para explicar os modos de agir e pensar das mulheres.

Dessa forma, em diferentes momentos históricos, a produção científica sobre o corpo da mulher serviu como base para a manutenção da hierarquia entre os sexos, e os hormônios têm contribuído para a produção da mulher como sujeito naturalmente desequilibrado.

Inicialmente, a ginecologia encontra no ovário e útero a elucidação para a fragilidade "física" e "mental" da mulher. Com isso, a biologia da mulher não definiria apenas aquilo que seu corpo é capaz de fazer, como gerar filhos, como discutimos anteriormente, mas se amplia para esclarecer os "aspectos psicológicos e intelectuais" desses seres inferiores.

Entretanto, os hormônios atualizaram tais preceitos, pois agora, ao invés de os médicos buscarem explicações no útero e ovário das mulheres, intervindo nessas partes do corpo a fim de recobrar a sanidade mental dessas, passam a prescrever hormônios para sanar esses problemas. A mulher passa a ser percebida a partir de um paradigma bioquímico, no qual as taxas de hormônios são medidas e reguladas a fim de explicar e controlar os comportamentos e afetos delas.

Porém, a administração de hormônios para mulheres não se encerra com o fim da sua vida reprodutiva, pois percebemos atualmente a crescente indicação de reposição hormonal para mulheres no climatério, que se articula com a promessa de juventude eterna e retorno do equilíbrio estético, físico e emocional da mulher (Menegon, 1998).

Destacamos a quarta controvérsia, na qual há um processo de naturalização da reposição do estrogênio e progesterona, hormônios que são percebidos como femininos na nossa sociedade, mas há discordâncias sobre a prescrição de testosterona para mulheres, mesmo que estudos apontem a diminuição das taxas dessa substância com a velhice (Edmonds \& Sanabria, 2016; Preciado, 2008).

Salientamos que os hormônios são apenas um dos atuantes da rede, que, em articulação com outros elementos, produzem efeitos diversos, mas esses efeitos não são estáveis, estão sempre mudando e apontando novas possibilidades de existência. 


\section{Hormônios na produção/regulação de masculinidades}

Enquanto as mulheres têm suas vidas governadas a partir da sua capacidade reprodutiva, os homens têm suas vidas geridas a partir do discurso biomédico pela produção de masculinidades, que se dá pela via sexual e pela regulação das taxas de testosterona.

Os homens, nas últimas décadas, têm sido capturados pelo campo da saúde, tendo sido a sua sexualidade o principal alvo desse processo até os dias de hoje. A produção de discursos normativos sobre o exercício da sexualidade tem afetado, principalmente, o processo de envelhecimento dos homens, que passam a fazer um uso crescente da testosterona (Silva, Marques, Lyra, Medrado, Leal, \& Raposo, 2012). Essa substância teria o efeito de garantir a agressividade, apetite sexual insaciável, aumento da massa muscular e da força, além da diminuição da fadiga.

Doutor Aguinaldo: após os 40 anos de idade o hormônio masculino, que se chama testosterona, pode diminuir em torno mais ou menos de 1\% ao ano. Ao redor de 15\% dos homens vão sofrer as consequências da diminuição desse hormônio, e isso vai levar a um quadro que era muito conhecido como andropausa, cujo nome está errado porque - diferentemente das mulheres, que a menopausa faz uma parada da produção dos hormônios - nos homens isso não ocorre. Existe só uma diminuição, então o nome correto desse conjunto de sinais e sintomas foi traduzido como Distúrbio Androgênico do Envelhecimento Masculino ou DAEM. O DAEM se caracteriza por uma série de sintomas que aparecem no homem, e vamos falar de alguns deles aqui: fadiga, malestar, desânimo, apatia, algumas vezes depressão, aumento da adiposidade de gordura no abdome formando a barriga, diminuição da massa muscular e principalmente diminuição do desejo sexual e algumas vezes queda da ereção. $E$ esse conjunto de sinais e sintomas, quando estiver associado ao baixo nível de hormônio no sangue, que é a testosterona, é feito então o diagnóstico de DAEM. E quem tem DAEM precisa ser tratado. A reposição da testosterona hoje em dia é um processo seguro, eficaz e com muita tranquilidade; o homem pode repor voltando aos seus níveis normais de testosterona e evitando com isso que ocorra queda com fraturas ósseas, diminuição da massa muscular, alterações da memória, alterações espaciais que nós chamamos de alterações cognitivas além de uma qualidade de vida saudável. É benéfica tanto no seio familiar quanto no sentimento de cada um. Todo homem após os 40 anos de idade que tenha algum sintoma deve procurar o médico urologista porque essa reposição de hormônio pode ser muito benéfica e proporcionar uma velhice saudável. (Bayer, 2010)

Percebemos, dessa forma, que os hormônios têm sido utilizados para naturalizar o binarismo sexual que destina a mulher à reprodução e o homem à sexualidade. Apesar da testosterona não ser exclusiva ao corpo dos homens e o estrogênio, progesterona e ocitocina não serem exclusivos do corpo das mulheres, tal ideia continua se perpetuando, como vimos ao longo do artigo (Oudshoorn, 1994).

Evidenciamos que os hormônios estão envolvidos em uma série de controvérsias, pois tais substâncias escapam da função para a qual elas foram inicialmente destinadas, provocando uma série de subversões e se entrelaçam com diferentes modos de subjetivação. 


\section{Considerações finais}

Ao analisarmos os agenciamentos produzidos pelos hormônios na conformação/deslocamentos de modos de subjetivação contemporâneos, estabelecemos controvérsias e colocamos em questão os padrões de sexo e sexualidade instituídos.

Tendo como referência o objetivo desta pesquisa, buscamos ainda estabelecer relações entre os saberes sobre os hormônios e a produção de efeitos de verdade; e analisar regulações da sexualidade e práticas de feminilização e masculinização agenciadas pelos hormônios.

No exercício de sintetizar a rede de controvérsias que estabelecemos ao longo deste escrito, apresentamos a teia, Figura 1:

\section{FIGURA - 1}

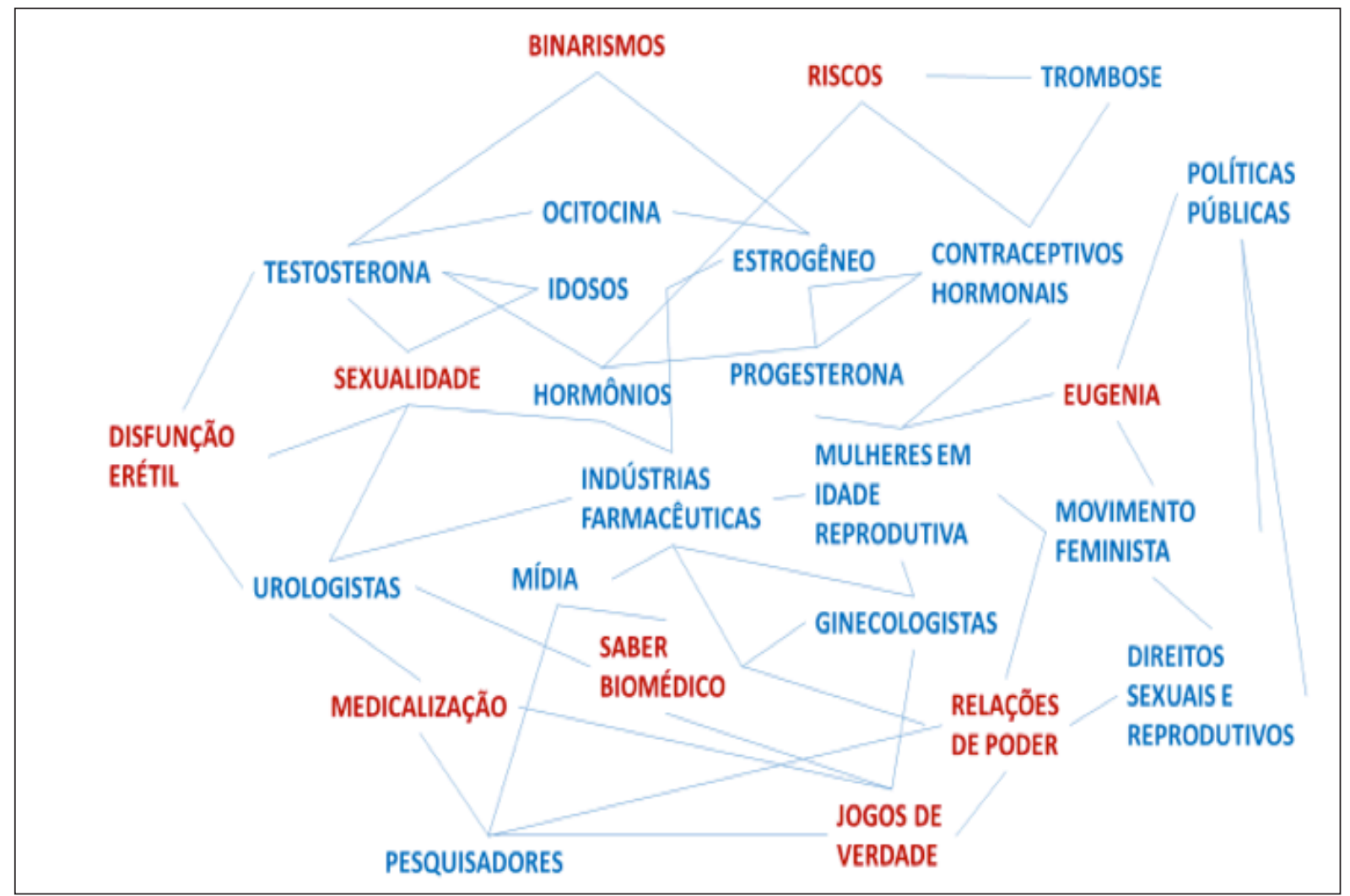

A teia apresenta uma disposição rizomática, sem início e fim (Deleuze \& Guattari, 2000). Os hormônios funcionaram como elementos centrais para facilitar o processo de análise, porém entendemos que esses se articulam com outros atuantes, para usarmos uma expressão de Bruno Latour, da rede produzindo diferentes efeitos. Os efeitos produzidos em rede não são fixos ou estáveis. Os atuantes da rede também são híbridos (na cor azul), rompendo com a lógica de que apenas os humanos possuem agência.

Acrescentamos, ainda, na rede, alguns conceitos (na cor vermelha) que nos ajudaram a pensar os agenciamentos produzidos pelos hormônios. Foucault e teóricos alinhados ao feminismo, além dos autores envolvidos na Teoria Ator-Rede, foram importantes interlocutores para elaboração do estudo. Dessa forma, optamos por explicitar os principais conceitos explorados. 
Ao longo desta pesquisa, podemos perceber que, de acordo com os encontros que os hormônios tiveram, tais enlaces produziram efeitos diversos, entre eles a renaturalização do modelo binário de sexo. Os vídeos delineiam a função reprodutiva da mulher como determinada biologicamente, pois a natureza dos hormônios que a constituem definem sua propensão para a maternidade e, como consequência, para a vida doméstica e os cuidados com a família. Em contrapartida, os homens são definidos pela grande quantidade de testosterona que circula em seus corpos, hormônio associado ao vigor sexual, força, energia, disposição e agressividade; com isso, os homens estariam fadados ao espaço público e ao exercício da sexualidade penetrativa.

O saber e poder biomédicos associam os hormônios à natureza feminina e masculina, produzindo como efeito de verdade modos de subjetivação mulheres e homens. Tais premissas normatizadoras instituem determinados modos de subjetivação e tentam restringir a diversidade de modos de viver. Aqueles que resistem aos padrões de feminilidade e masculinidade instituídos são submetidos a sanções, que muitas vezes envolvem a patologização da sua existência.

O binarismo de sexo é reatualizado com a substancialização da diferença sexual a partir dos hormônios. Há, então, uma essencialização do que é ser homem e do que é ser mulher, antes com base na anatomia da genitália, posteriormente, nas gônadas e agora tendo os hormônios como referência. O dualismo de sexo característico da nossa sociedade tem se renovado com os hormônios, delimitando este aspecto da vida ao plano da biologia, supostamente natural e imutável. O homem continua sendo construído como oposto à mulher, sendo, dessa forma, criaturas biologicamente diferentes, e a suposição de tal diferença produz efeitos em diferentes âmbitos da vida.

É justamente a instabilidade e as controvérsias que envolvem o binarismo de sexo que incitam a constante reatualização de práticas essencialistas. A feminilização e masculinização produzidas pelos hormônios são práticas, ações, efeitos, e não a essência dos hormônios. Assim, compreendemos que os hormônios produzem efeitos diversos, dependendo dos laços que essas substâncias estabelecem em rede, que envolvem questões políticas, econômicas, científicas, morais etc. Isso posto, esta pesquisa coloca em questão os dualismos: homem e mulher, natureza e cultura, natural e artificial.

A produção científica sobre os hormônios é permeada por diversas outras relações, por isso é necessário questionar os determinismos produzidos pelo cientificismo biológico e os imperativos associados a uma noção genérica de saúde como norma.

A sexualidade, por exemplo, tornou-se um indicador de saúde que precisa ser estimulado durante toda a vida do sujeito. Há um predomínio das explicações biologicistas sobre a sexualidade, tornando-a uma função natural e orgânica do ser humano, sendo, então, passível de investigação. Tal concepção tornou-se base para o desenvolvimento do atual mercado de substâncias voltado para a sexualidade. Dessa maneira, parece não ter possibilidades para compreender o sexo para além das explicações biomédicas, que o traduzem em termos bioquímicos e orgânicos, estabelecendo padrões de se viver.

Os hormônios articulam-se, ainda, com uma perspectiva individualista de existência, na qual cabe a cada um administrar tais substâncias a fim de atingir os padrões de normalidade instituídos e alcançar a felicidade. Destarte, os conceitos de molecularização, optimização, subjetificação, expertise e bioeconomia propostos por Rose (2013) nos ajudaram também a compreender a dinâmica de transformações que envolvem a noção de corpo saudável centrada no autogerenciamento individual. 
Na nossa sociedade, a saúde perpassa questões morais e individuais, na qual o sujeito precisa se informar sobre práticas de cuidado, como as oferecidas pelos vídeos da Bayer. Por uma via farmacológica e individualista, as melhorias do desempenho e funcionalidade são articuladas aos regimes de verdade, produzindo, assim, determinados modos de viver.

Portanto, os hormônios são indicados não só para o tratamento de problemas de saúde, mas também para a prevenção de possíveis mazelas que possam vir a acometer o sujeito, governando o presente como tentativa de controlar o futuro. "As técnicas e recursos biotecnológicos produzem novos objetos e questões, antes inconcebíveis ou impossíveis de serem formulados, engendrando novas formas de vida, novas formas de compreensão da vida e, portanto, novos modos de existência” (Hüning, 2008, p. 106).

As biotecnologias são importantes referências para os modos de subjetivação na atualidade, e os hormônios são um desses atuantes, que possibilitam a inteligibilidade de novos modos de se relacionar consigo e com os outros. Os hormônios têm produzido efeitos nas formas corporais, nos afetos, nas condutas.

A partir da administração dos hormônios são instituídas normas sobre o que é saúde, o que é risco, como controlar o futuro, o que é verdade, quem tem o direito à fala, como se deve exercer a sexualidade, com quem se relacionar sexualmente, quem pode ou não administrar determinadas substâncias, quem deve se reproduzir, como e quando é autorizada a reprodução etc.

Quando lançamos um olhar mais atento para a potente constituição desse novo mercado de produtos e medidas de desempenho, percebemos o quanto ele tem sido eficaz na conformação de determinados marcos de referência em termos de sexualidade e gênero, definidos de forma bastante estrita e bem distantes das reivindicações em prol do respeito à diversidade, seja de práticas distintas, seja de comportamentos alternativos ou de identidades fluidas. (Rohden, Russo, \& Giami, 2014, p. 26)

Ideais de saúde, juventude, beleza, família, masculinidades, feminilidades, desempenho sexual e sexualidade se associam com os hormônios, produzindo determinados modos de viver. Os hormônios, de forma isolada, não agenciam as controvérsias que assinalamos ao longo deste estudo. Sem a tentativa de controle do futuro, os hormônios não seriam, ao mesmo tempo, produtores e protetores de riscos; sem as políticas de controle da natalidade e o movimento feminista, os hormônios não proporcionariam, concomitantemente, a liberdade sexual da mulher e o controle dos seus corpos.

Quando nos propomos a cartografar controvérsias, pensamos em uma rede sempre em fluxos e deslocamentos, com diferentes elementos que estão constantemente se encontrando e se afastando. Não há, nesse sentido, atuantes isolados, mas agenciamentos em rede.

Esta pesquisa não buscou produzir certezas, mas novas inquietações que possam levar a outras pesquisas. Focamos, neste estudo, principalmente nos discursos oficiais, produzidos pelo saber biomédico e difundido a partir de vídeos da empresa farmacêutica Bayer, mas ficam questões ainda sobre como os sujeitos têm se produzido no cotidiano a partir da administração dos hormônios ou, mais precisamente, que efeitos são relatados? Como se configura a dinâmica entre tentativas de reprodução linear do discurso hegemônico e os jogos de resistência? 
Podemos perceber, ainda, no que se refere à hormonização dos corpos, que os estudos e discursos sobre as mulheres têm sido mais produzidos e disseminados, na nossa sociedade, se comparados aos homens. Com isso, é importante que mais pesquisadores se dediquem a analisar a relação dos homens com o processo reprodutivo e de cuidado, como, por exemplo, a possibilidade de comercialização dos contraceptivos masculinos, ou ainda da amamentação por homens.

Não buscamos estabelecer generalizações ou conclusões definitivas com esses escritos, mas almejamos que este estudo tenha possibilitado o questionamento da naturalização dos efeitos dos hormônios, trazendo tais substâncias para o debate ético-político, a fim de produzir novos devires mais criativos e potentes.

\section{Referências}

Bayer. (2010, novembro, 30). Uso de métodos anticoncepcionais - planejamento familiar - BLOCO 1. [Arquivo de vídeo]. Recuperado de https://www.youtube.com/watch?v=-xG2j-1n7xs

Bayer. (2011a, janeiro, 27). Os principais avanços da medicina que contribuiram para a qualidade de vida da mulher. [Arquivo de vídeo]. Recuperado de https://www.youtube.com/ watch? $=\mathrm{gLd} 87 \mathrm{wuLHDs}$

Bayer. (2011b, setembro, 14). GIRLS TALK TV; tomando a pílula (episódio 3). [Arquivo de vídeo]. Recuperado de https://www.youtube.com/watch?v=blqogCuJY2s

Deleuze, G. \& Guattari, F. (2000). Mil Platôs: Capitalismo e esquizofrenia (Vol. 1). Rio de Janeiro: Ed. 34. (Coleção TRANS)

Edmonds, A. \& Sanabria, E. (2016). Entre saúde e aprimoramento: a engenharia do corpo por meio de cirurgias plásticas e terapias hormonais no Brasil. História, Ciências, Saúde (Manguinho), 23(1), 193-210.

Foucault, M. (2009). História da sexualidade I: a vontade de saber (19a ed.). Rio de Janeiro: Graal.

Foucault, M. (2010). Ética, Sexualidade, Política (Vol. 5). Rio de Janeiro: Forense Universitária. (Coleção Ditos e Escritos). (Original publicado em ano 1994)

Galindo, D., Vilela, R., \& Moura, M. (2012). Uma dose queer: performances tecnofarmacológicas no uso informal de hormônios entre travestis. In L. Souza, D. Galindo, \& V. Bertoline (Orgs.), Gênero, corpo e ativismos (pp. 171-196). Cuiabá: UFMT.

Hüning, S. M. (2008). O sujeito biotecnológico na viagem pelo reino das batatas transgênicas, porquinhos fosforescentes e almas codificadas. Tese de Doutorado, Programa de Pós-graduação em Psicologia, Pontifícia Universidade Católica do Rio Grande do Sul, Porto Alegre, RS. Recuperado de http://tede.pucrs.br/tde arquivos/20/TDE-2008-05-09To55513Z-1251/ Publico/400848.pdf

Latour, B. (2001). A Esperança de Pandora: ensaios sobre a realidade dos estudos científicos. Bauru, SP: EDUSC.

Latour, B. (2007). La cartographie des controverses. Recuperado de http://www.tchnologyreview.fr $/$ ? id $=65$. 
Latour, B (2009). Jamais fomos modernos: ensaio de antropologia simétrica (2a ed.). Rio de Janeiro: Editora 34 .

Latour, B. (2012). Reagregando o social: uma introdução à teoria do Ator-Rede. Salvador: Edufba.

Matos, M. (2003). Delineando corpos: as representações do feminino e do masculino no discurso médico. In M. Matos \& R. Soihet (Orgs.), O corpo feminino em debate (pp. 107-127). São Paulo: UNESP.

Menegon, V.(1998). Menopausa: imaginário social e conversas do cotidiano. Dissertação de Mestrado, Programa de Pós-graduação em Psicologia Social, Pontifícia Universidade Católica, São Paulo/SP.

Méllo, R. P. (2006). A construção da noção de abuso sexual infantile. Belém: EDUFPA.

Moreira, M. C. (2014). “O que foi feito, amigo, de tudo que a gente sonhou?” Uma cartografia da atuação de Organizações da Sociedade Civil no fortalecimento da democracia. Tese de Doutorado, Programa de Pós-graduação em Psicossociologia de Comunidades e Ecologia Social, Universidade Federal do Rio de Janeiro, Rio de Janeiro, RJ. Recuperado de http://pos.eicos.psicologia.ufrj.br/wp-content/uploads/MarianaMoreiraD2014.pdf

Nardi, H. (2006). Ética, trabalho e subjetividade: trajetórias de vida no contexto das transformações do capitalismo contemporâneo. Porto Alegre: UFRGS.

Neira, M. \& Lippi, B. (2012). Tecendo a Colcha de Retalhos: a bricolagem como alternativa para a pesquisa educacional. Educação E̊ Realidade, 37(2), 607-625.

Oudshoorn, N. (1994). Beyond the natural body: an archeology of sex hormones. London: Routledge.

Pedro, J. (2003). As representações do corpo feminino nas práticas contraceptivas, abortivas e no infanticídio - século XX. In M. Matos \& R. Soihet (Orgs.), O corpo feminino em debate (pp. 157-176). São Paulo: Editora UNESP.

Preciado, B. (2008). Testo Tonqui. Madri: Calpe.

Rohden, F. (2000). Uma Ciência da Diferença: Sexo, Contracepção e Natalidade na Medicina da Mulher. Tese de Doutorado, Programa de Pós-graduação em Antropologia, Universidade Federal do Rio de Janeiro, Rio de Janeiro/RJ.

Rohden, F. \& Russo, J. (2011). Diferenças de gênero no campo da sexologia: novos contextos e velhas definições. Revista de Saúde Pública, 45(4), p. 722-729.

Rohden, F., Russo, J., \& Giami, A. (2014). Novas tecnologias de intervenção na sexualidade: o panorama latino-americano. Sexualidad, Salud y Sociedad, 17, 10-29. http://dx.doi. org/10.1590/1984-6487.sess.2014.17.04.a

Rose, N. (2013). A política da própria vida: Biomedicina, poder e subjetividade no século XXI. São Paulo: Pulus.

Silva, V., Marques, A. P., Lyra, J., Medrado, B., Leal, M., \& Raposo, M. (2012). Satisfação Sexual entre Homens Idosos Usuários da Atenção Primária. Saúde e Sociedade, 21(1), 171-180. http:// dx.doi.org/10.1590/So 104-12902012000100017

Souza, L., Galindo, D., \& Bertoline, V. (Orgs.). (2012). Gênero, corpo e ativismos. Cuiabá: UFMT. 
Spink, P. (2004). Análise de documentos de domínio público. In Práticas discursivas e produção de sentido no cotidiano: aproximações teóricas e metodológicas (3a ed., pp. 100-127). São Paulo: Cortez.

Spink, M. J., Brigagão, J., Nascimento, V., \& Cordeiro, M. (Orgs.). (2014). A produção de informação na pesquisa social: compartilhando ferramentas. Rio de Janeiro: Centro Edelstein de Pesquisas Sociais.

\section{JULIANA VIEIRA SAMPAIO \\ http://orcid.org/0000-0001-5770-244X}

Psicóloga e doutora em Psicologia pela Universidade Federal de Pernambuco, Recife.

Endereço: Av. da Universidade, 2762, Benfica - CEP: 60.020-180 Fortaleza/CE - Área 2 do Centro de Humanidades - Bloco Didático Prof. Ícaro de Sousa Moreira.

E-mail: julianavsampaio@,hotmail.com

\section{BENEDITO MEDRADO}

https://orcid.org/0000-0002-1085-5024

Doutor em Psicologia Social; Professor do Departamento de Psicologia da UFPE (cursos de graduação e pós-graduação); coordenador do Núcleo Feminista de Pesquisas em Gênero e Masculinidades (Gema/UFPE) e um dos fundadores da ONG Instituto PAPAI.

E-mail: beneditomedrado@gmail.com

\begin{tabular}{|c|c|}
\hline Histórico & $\begin{array}{l}\text { Submissão: 17/06/2017 } \\
\text { Revisão: 09/03/2018 } \\
\text { Aceite: 03/10/2019 }\end{array}$ \\
\hline Contribuição & $\begin{array}{l}\text { Concepção: JVS; BM. } \\
\text { Coleta de dados: JVS. } \\
\text { Análise de dados: JVS; BM. } \\
\text { Elaboração do manuscrito: JVS; BM. } \\
\text { Final aprovação do manuscrito: JVS; BM. }\end{array}$ \\
\hline Financiamento & $\begin{array}{l}\text { Coordenação de Aperfeiçoamento de Pessoal de Nível } \\
\text { Superior (CAPES) - bolsa de doutorado para Juliana Vieira } \\
\text { Sampaio. }\end{array}$ \\
\hline $\begin{array}{l}\text { Consentimento de } \\
\text { uso de imagem }\end{array}$ & $\begin{array}{l}\text { Não se aplica. Todos os documentos analisados são de acesso } \\
\text { livre. }\end{array}$ \\
\hline $\begin{array}{l}\text { Aprovação, ética } \\
\text { e consentimento }\end{array}$ & Não se aplica. \\
\hline
\end{tabular}

